\title{
Correlation of receptor density and mRNA expression patterns in the human cerebral cortex
}

\author{
Murgaš Matej, Michenthaler Paul, Reed Murray Bruce, Gryglewski Gregor, \\ Lanzenberger Rupert
}

Department of Psychiatry and Psychotherapy, Medical University of Vienna, Austria

Keywords: transcriptomics, human brain proteome, microarray, RNA sequencing, autoradiography

Correspondence to:

Prof. Rupert Lanzenberger, MD, PD

NEUROIMAGING LABS (NIL) - PET, MRI, EEG, TMS \& Chemical Lab

Department of Psychiatry and Psychotherapy

Medical University of Vienna, Waehringer Guertel 18-20, 1090 Vienna, AUSTRIA

Tel: +43-1-40400-35760

Email: rupert.lanzenberger@meduniwien.ac.at

http://www.meduniwien.ac.at/neuroimaging 


\section{Abstract:}

Changes in distribution of associated molecular targets have been reported across several neuropsychiatric disorders. However, the high-resolution topology of most proteins is unknown and simultaneous in vivo measurement in multi-receptor systems is complicated. To account for the missing proteomic information, mRNA transcripts are typically used as a surrogate. Nonetheless, posttranscriptional and post-translational processes might cause the discrepancy between the final distribution of proteins and gene expression patterns. Therefore, this study aims to investigate ex vivo links between mRNA expression and corresponding receptor density in the human cerebral cortex.

To this end, autoradiography data on the density of 15 different receptors in 38 brain regions were correlated with the expression patterns of 50 associated genes derived from microarray data $(\mathrm{mA})$, RNA sequencing data (RNA-Seq) provided by the Allen Human Brain Atlas and predicted mRNA expression patterns (pred-mRNA). Spearman's rank correlation was used to evaluate the possible links between proteomic data and mRNA expression patterns.

Correlations between mRNA and protein density varied greatly between targets: Positive associations were found for e.g. the serotonin $1 \mathrm{~A}$ (pred-mRNA: $r_{s}=0.708 ; \mathrm{mA}: r_{s}=0.601$ ) or kainate receptor (predmRNA: $r_{s}=0.655 ; m A: r_{s}=0.601 ;$ RNA-Seq: $\left.r_{s}=0.575\right)$, while most of the investigated target receptors showed low or negative correlations.

The high variability in the correspondence of mRNA expression and receptor warrants caution when inferring the topology of molecular targets in the brain from transcriptome data. This highlights the longstanding value of molecular imaging data and the need for comprehensive proteomic data. 


\section{Introduction}

To unravel underlying molecular mechanisms in the human brain, it is of paramount importance to establish an in vivo analysis method of multiple receptor systems in both healthy persons and patients. Currently, in vivo imaging modalities are usually limited to specific receptors; e.g positron emission tomography (PET), which necessitates the use of a radiotracer to allow for the investigation of very few targets. Moreover, systems utilizing two tracers are currently under development, whilst the number of targets concurrently detectable and quantifiable in PET will remain critically limited for the foreseeable future, as currently dual tracer PET is developed for a limited application (e.g. hepatocellular carcinoma) and remains prohibitively expensive (Filippi et al., 2019; Lu et al., 2019). Current studies suggest that it is highly unlikely that changes in a singular receptor system confer all symptoms of brain disorders as complex as, e.g. depression (Villas Boas et al., 2019). The numerous pharmacological targets of drugs used in the treatment of neuropsychiatric disorders further strengthen this claim. Furthermore, many drugs used in contemporary psychopharmacological treatment show efficacy in different psychiatric disorders, pointing towards shared mechanisms between them (Lamers et al., 2011; Rainer et al., 2012).

In recent years, neuroimaging techniques quantifying protein distribution (e.g. PET) have become commonplace in psychiatric research (Lui et al., 2016), e.g. to investigate possible effects of electroconvulsive therapy in depressed patients (Baldinger-Melich et al., 2019) or the effect of bright light therapy in patients with affective disorders (Spies et al., 2018). However some of the basic hypotheses of modern psychiatry, including the monoamine hypothesis, still stem from decade-old post mortem findings (Cosci and Chouinard, 2019; Horton, 1992). To this end, shedding light on associations between ex vivo data generated using radioligands to mark specific structures (such as receptors, enzymes, etc.) and their underlying mRNA expression patterns could pave the way toward more complete analysis and potentially allow for extrapolation of protein distributions based on molecular information. 
Modern multimodal atlases like the Allen Human Brain Atlas (AHBA) provide valuable insights into the cerebral mRNA expression patterns and by this virtue might allow estimation of the respective protein receptor abundance and distribution. Previous studies have demonstrated similarities between mRNA expression patterns and the distribution of certain receptors, e.g. serotonin $1 \mathrm{~A}$ and $2 \mathrm{~A}$ (Beliveau et al., 2017; Komorowski et al., 2017; Unterholzner et al., 2020), dopamine D3 (Komorowski et al., 2020b), or enzymes (Lohith et al., 2017) measured using PET. Moreover, associations between mRNA expression patterns and task-specific activations measured by fMRI were revealed for reward and emotion processing(Komorowski et al., 2020a). Contrary to these findings, no relations were discovered between protein distribution and gene expression of monoamine oxidase A (Godbersen et al., 2021) and serotonin transporter (Komorowski et al., 2017). Preliminary investigations have also shown mixed results when comparing transcriptomic data to receptor densities measured by autoradiography (Murgas et al., 2020 , 2021a, 2021b, 2021c).

Uncovering stable defining correlations across different brain regions, mRNA expression and resulting gene product abundance may enable future estimation of protein distribution based on initial gene expression patterns and potentially even support personalized treatments in psychiatry. Notwithstanding, a number of challenges remain as studies looking for associations between mRNA expression and protein distribution often fail to deliver significant positive results and even significant results are inconsistent in their findings (Arnatkevičiūtè et al., 2019). In the current study, we compared a collection of cortical multi-receptor proteomic autoradiography fingerprints measured by Jülich Research Centre (Zilles and Palomero-Gallagher, 2017)to a corresponding dataset of ex vivo gene expression patterns adopted from Allen Human Brain Atlas measures. 


\section{Materials and Methods}

To elucidate possible links between molecular mechanisms and protein distributions, we compare the spatial distribution of 15 different receptors and mRNA transcripts associated with them or their subunits. In particular, we study three ionotropic glutamate receptors - AMPA, Kainate and NMDA; GABA receptors - $G A B A_{A}, G A B A_{A / B Z}$ (benzodiazepine binding site) and $G A B A_{B}$; cholinergic receptors muscarinic $M_{1}, M_{2}, M_{3}$ and nicotinic $\alpha_{4} \beta_{2}$; adrenoceptors $\alpha_{1}$ and $\alpha_{2}$; serotonin receptors 5-HT 1 and 5$H T_{2}$; dopamine receptor $D_{1}$. The full list of investigated relations is in Table 1.

\begin{tabular}{|l|l|}
\hline Receptor & Associated gene expressions \\
\hline AMPA & GRIA1, GRIA2, GRIA3, GRIA4 \\
\hline Kainate & GRIK1, GRIK2, GRIK3, GRIK4 \\
\hline NMDA & GRIN1, GRIN2A, GRIN2B, GRIN2C, GRIN2D, GRIN3A, GRIN3B \\
\hline GABA ${ }_{A}$ & $\begin{array}{l}\text { GABRA1, GABRA2, GABRA3, GABRA4, GABRA5, GABRA6, GABRB1, GABRB2, GABRB3, } \\
\text { GABRD, GABRE, GABRG1, GABRG2, GABRG3, GABRP, GABRQ }\end{array}$ \\
\hline $\mathrm{GABA}_{\mathrm{B}}$ & GABBR1, GABBR2 \\
\hline $\mathrm{GABA}_{\mathrm{A} / \mathrm{BZ}}$ & $\begin{array}{l}\text { GABRA1, GABRA2, GABRA3, GABRA5, GABRB1, GABRB2, GABRB3, GABRD, GABRE, } \\
\text { GABRG1, GABRG2, GABRG3, GABRP, GABRQ }\end{array}$ \\
\hline $\mathrm{M}_{1}$ & CHRM1 \\
\hline $\mathrm{M}_{2}$ & CHRM2 \\
\hline $\mathrm{M}_{3}$ & CHRM3 \\
\hline$\alpha_{4} \beta_{2}$ & CHRNA4, CHRNB2 \\
\hline$\alpha_{1}$ & ADRA1A, ADRA1B, ADRA1C \\
\hline$\alpha_{2}$ & ADRA2A, ADRA2B, ADRA2C \\
\hline $5-\mathrm{HT}_{1 \mathrm{~A}}$ & HTR1A \\
\hline $5-\mathrm{HT}_{2}$ & HTR2A, HTR2B, HTR2C \\
\hline $\mathrm{D}_{1}$ & DRD1 \\
\hline
\end{tabular}

Table 1: Overview of target receptors and their corresponding gene expression patterns associated with the receptor or its possible subunit.

\subsection{Receptor distribution}

In this data-driven approach, we utilize a readily available dataset (Zilles and Palomero-Gallagher, 2017) comprising of autoradiography data (autoRTG) acquired from the brains of three healthy donors (72-77 years old, 2 males) as a source for multi-receptor profiles across 38 cortical areas defined in the original paper of the data. Regional values represent mean receptor density ( $\mathrm{fmol} / \mathrm{mg}$ ) over all cortical layers. 


\subsection{Gene expression}

Corresponding mRNA expression data are adopted from the AHBA (ALLEN Human Brain Atlas, 2013; Hawrylycz et al., 2012), which provide data on a variety of transcripts and a considerable number of sampling sites. The atlas contains microarray data $(\mathrm{mA})$ from six adult donors (24-57 years old, 5 males) and additional RNA sequencing (RNA-Seq) data of two donors. To account for the spatially incomplete data of AHBA, we also make use of predicted mRNA expression patterns (pred-mRNA). Briefly, AHBA samples for microarray data are mirrored along the $\mathrm{x}$-axis of MNI space to overcome a substantial difference in the number of samples from the left and right hemispheres in AHBA. Utilizing kriging via Gaussian process regression, continuous mRNA expression across the cortex is predicted (Gryglewski et al., 2018). Maps are publicly available at http://www.meduniwien.ac.at/neuroimaging/mRNA.html. pred-mRNA are further represented by mean regional values of 38 cytoarchitectonicaly distinct areas defined in Julich-Brain atlas (Amunts et al., 2020) (Figure 1, Suppl. Table 1).

Microarray data from the AHBA data set consists of 3702 samples that need to be accordingly preprocessed (Arnatkevičiūtė et al., 2019) . Therefore, we first identify probes that have a significantly different mean signal from the background and at the same time the difference between their background-subtracted signal and background is more than 2.6 (ALLEN Human Brain Atlas, 2013). As there are typically multiple probes associated with one target within one sample, the mean value is calculated for the particular sample. Next, samples are assigned to a particular region based on their spatial location. This is achieved by warping the Colin27 MNI template (Holmes et al., 1998) to the subjects T1 using SPM12 (The Wellcome Centre for Human Neuroimaging, www.fil.ion.ucl.ac.uk) to the individual space of each brain from AHBA separately. As a result, each of the 1390 microarray samples is assigned to 38 regions from the Julich-Brain atlas. To account for the inter-subject variability of AHBA mA data, scaled robust sigmoid normalization is applied (Fulcher et al., 2013). Subsequently, average regional values are calculated as the mean over the probe values, for each gene expression. 

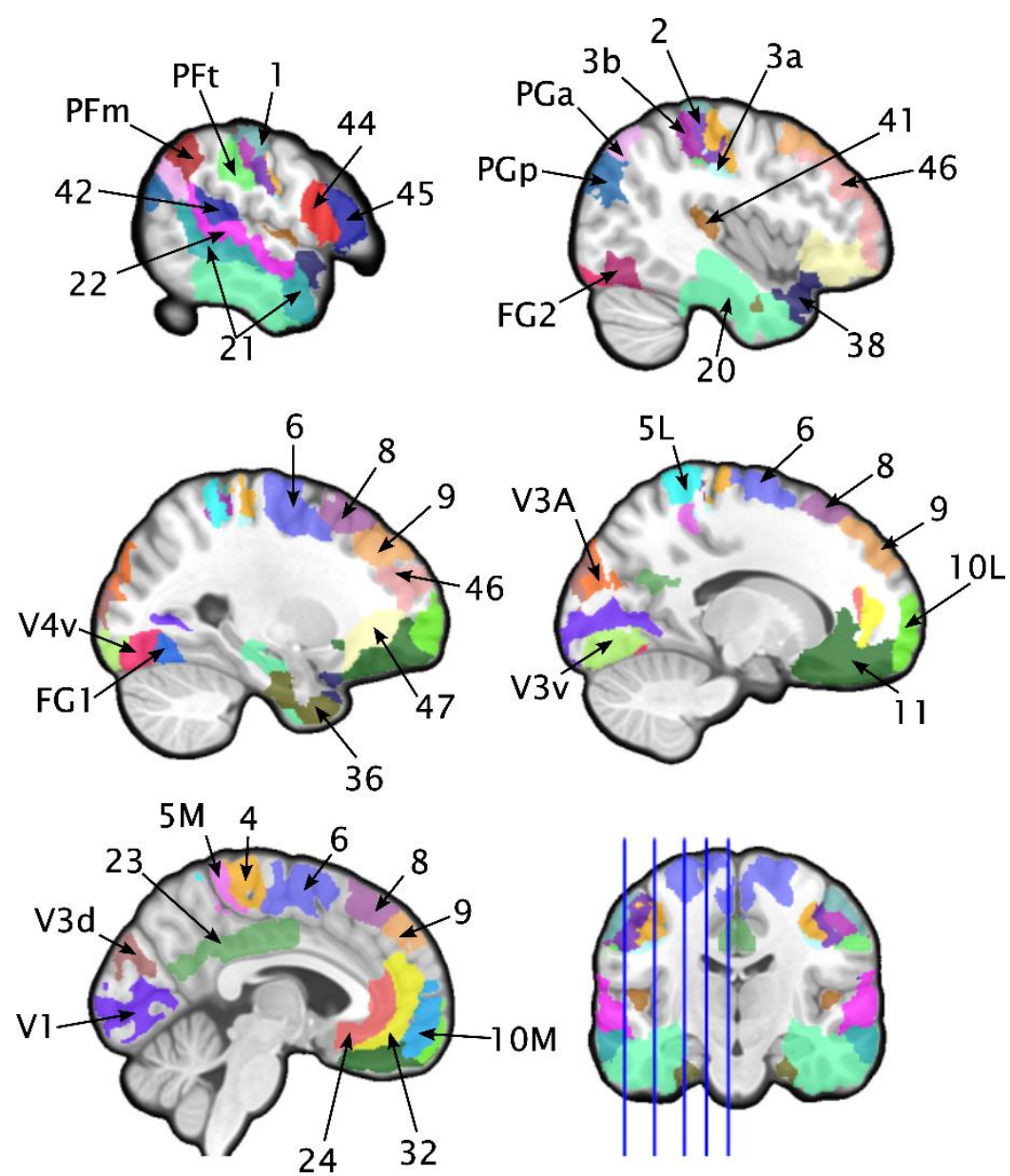

Figure 1: Visual representation of ROIs included in analysis. Diverse colors indicate covered areas. For the full list of the regions see supplementary table 1.

With the current trend in the RNA analysis directing to the more robust and reliable gene expression quantification (Wang et al., 2014), we also make use of two additional RNA-Seq data available from the AHBA (ALLEN Human Brain Atlas, 2013; Hawrylycz et al., 2012; Shen et al., 2012). The deformation fields from the previous step were additionally used to assign the 242 RNA sequencing samples to individual regions, resulting in 165 RNASeq samples associated with the selected regions. As not all of the selected areas are associated with the samples for RNA-Seq data only those ROls with at least 1 independent data point reported were retained, resulting in 34 regions from RNASeq for analysis. Subsequently, all samples are averaged region-wise and represent the mean Transcripts Per Kilobase Million (TPM). To investigate the discrepancy between RNA-Seq data and the other 2 data set based on microarray data, we compared RNA-Seq data to pred-mRNA and mA. 


\subsection{Statistical analysis}

We perform Spearman's rank correlation analysis between receptor densities, as measured by autoradiography across all cortical layers of all ROIs and the abovementioned prediction of mRNA expression, pre-processed microarray data and RNA-Seq data obtained from Allen Human Brain atlas. Correlation coefficient $r_{s}$ was considered low if its absolute value was below 0.5 (Cohen, 1992).

The significance of the correlation test is assessed by the spatial autocorrelation preserving, generative null modeling framework implemented in Brainsmash (Burt et al., 2020). In particular, 10,000 surrogate maps preserving 5 nearest neighbors are created for each transcript and subsequently correlated with respective protein density data. The proportion of the absolute value of correlation coefficients produced by the surrogate maps higher than the absolute value of empirical data calculated correlation coefficient defines $p$-value $\left(p_{S A}\right)$. All $p$-values are corrected for multiple testing using Bonferroni correction for the number of targets and the result is considered as significant when $\mathrm{p}_{\mathrm{SA}}<0.05$. Statistical analyses are performed using MATLAB (R2018b, MathWorks, Natick, USA). 


\section{Results}

\subsection{Predicted mRNA expression}

The primary analysis correlating interpolated mRNA expression based on the AHBA to autoradiography data provides a diverse picture. Comparison between mRNA expression and receptor density of kainate receptor and GRIK1, GRIK2; GABA $A_{A}$ receptor and GABRA1, GABRA4, GABRA6, GABRB2, GABRG2, GABRG3; muscarinic acetylcholine receptor $\mathrm{M}_{3}$ and $C R H M 3$; adrenoceptors $\alpha_{1}$ and $A D R A 1 B$; $\alpha_{2}$ and $A D R A 2 A$ and serotonin $1 A$ receptor and HTR1A (see Figure 2a) reveal strong positive associations with almost all Spearman's correlation coefficient above 0.5 (see Table 2). On the other hand, the correlation between levels of mRNA and associated protein abundance as measured by autoradiography unveil significant negative correlations for $\mathrm{GABA}_{\mathrm{A}}$ receptor and $G A B R A 3, \mathrm{GABRA5}$ and GABRB1 (Table 2), (Figure 2b). Despite a small number of strong links between mRNA transcripts and target receptor distributions, most of the comparisons yield weak non-significant. The overviews of all correlation results are listed in supplementary tables 2-6.

\begin{tabular}{|c|c|c|c|c|}
\hline Receptor & Gene ID & Gene & $\mathbf{r}_{\mathrm{s}}$ & $p_{\text {SA }}$ \\
\hline $5-\mathrm{HT}_{1 \mathrm{~A}}$ & HTR1A & serotonin receptor $1 \mathrm{~A}$ & 0.708 & 0.000 \\
\hline $\mathrm{GABA}_{\mathrm{A}}$ & GABRG2 & $\mathrm{GABA}_{\mathrm{A}}$ receptor subunit $\gamma 2$ & 0.738 & 0.000 \\
\hline $\mathrm{GABA}_{\mathrm{A}}$ & GABRG3 & $\mathrm{GABA}_{\mathrm{A}}$ receptor subunit $\gamma 3$ & 0.658 & 0.000 \\
\hline $\mathrm{GABA}_{\mathrm{A}}$ & GABRA4 & $\mathrm{GABA}_{\mathrm{A}}$ receptor subunit $\alpha 4$ & 0.607 & 0.008 \\
\hline $\mathrm{GABA}_{\mathrm{A}}$ & GABRA6 & $\mathrm{GABA}_{\mathrm{A}}$ receptor subunit $\alpha 6$ & 0.597 & 0.005 \\
\hline $\mathrm{GABA}_{\mathrm{A}}$ & GABRA1 & $\mathrm{GABA}_{A}$ receptor subunit $\alpha 1$ & 0.575 & 0.011 \\
\hline $\mathrm{GABA}_{\mathrm{A}}$ & GABRB2 & $\mathrm{GABA}_{A}$ receptor subunit $\beta 2$ & 0.532 & 0.029 \\
\hline Kainate & GRIK1 & Glu ionotropic receptor kainate type subunit 1 & 0.655 & 0.009 \\
\hline Kainate & GRIK2 & Glu ionotropic receptor kainate type subunit 2 & 0.629 & 0.014 \\
\hline$M_{3}$ & CHRM3 & cholinergic receptor muscarinic 3 & 0.498 & 0.038 \\
\hline$\alpha_{1}$ & ADRA1B & adrenoceptor $\alpha 1 \mathrm{~B}$ & 0.522 & 0.014 \\
\hline$\alpha_{2}$ & ADRA2A & adrenoceptor $\alpha 2 \mathrm{~A}$ & 0.488 & 0.021 \\
\hline $\mathrm{GABA}_{\mathrm{A}}$ & GABRA3 & $\mathrm{GABA}_{A}$ receptor subunit $\alpha 3$ & -0.638 & 0.002 \\
\hline $\mathrm{GABA}_{\mathrm{A}}$ & GABRB1 & $\mathrm{GABA}_{A}$ receptor subunit $\beta 1$ & -0.577 & 0.006 \\
\hline $\mathrm{GABA}_{\mathrm{A}}$ & GABRA5 & $\mathrm{GABA}_{\mathrm{A}}$ receptor subunit $\alpha 5$ & -0.565 & 0.020 \\
\hline
\end{tabular}

Table 2: Gene expressions represented by predicted mRNA patterns significantly $\left(p_{S A}<0.05\right)$ correlated with receptor distributions. Negative correlations are listed at the bottom of the table. 
a

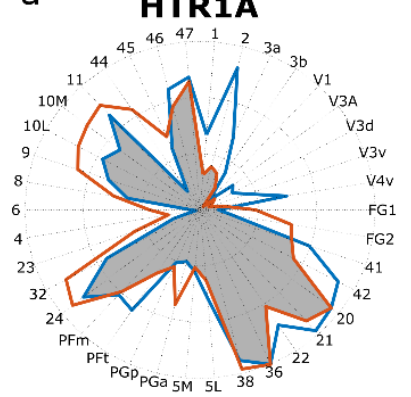

GABRA1

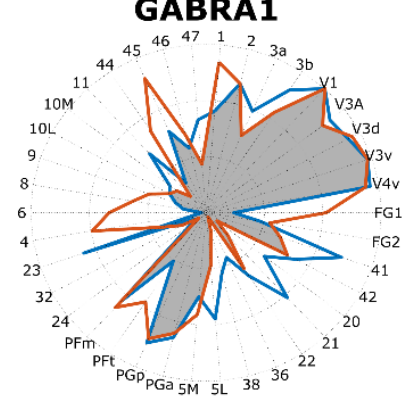

GABRB 2

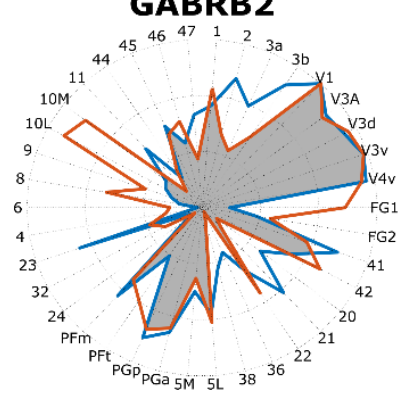

CHRM3

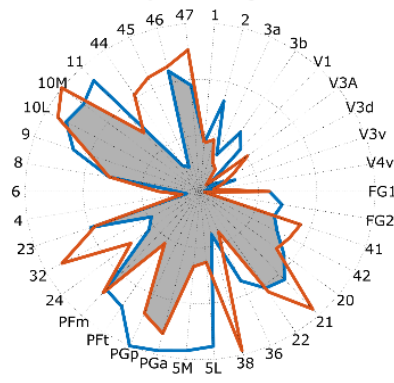

b

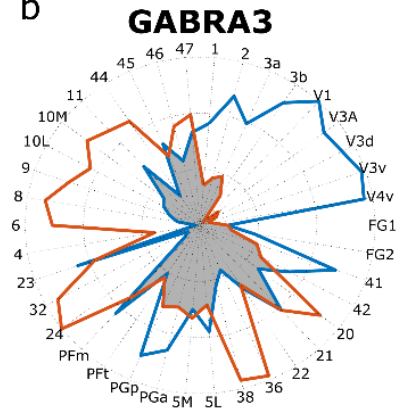

GRIK1

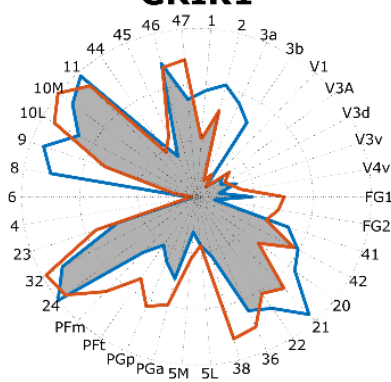

GABRA4

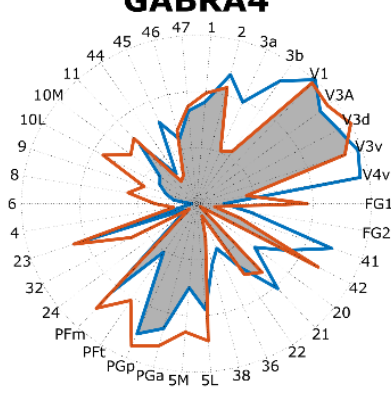

GABRG2

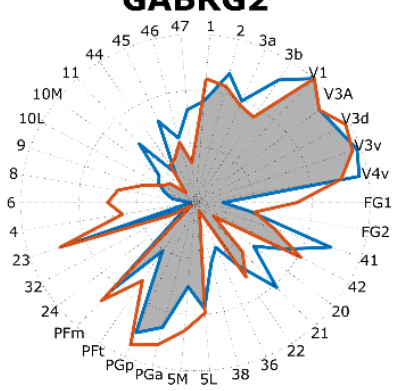

ADRA1B

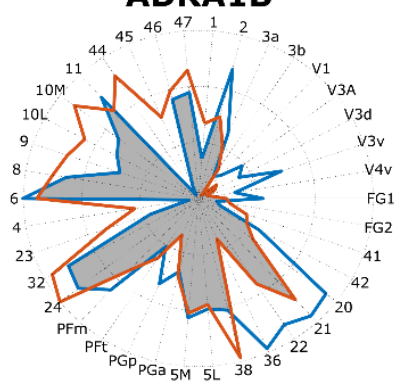

GABRA5

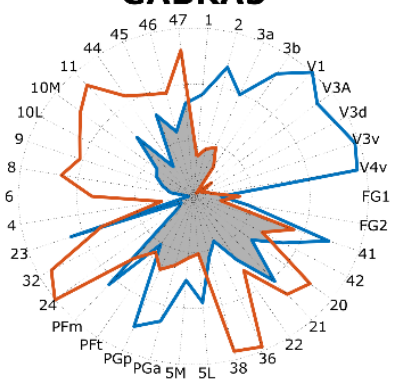

GRIK2

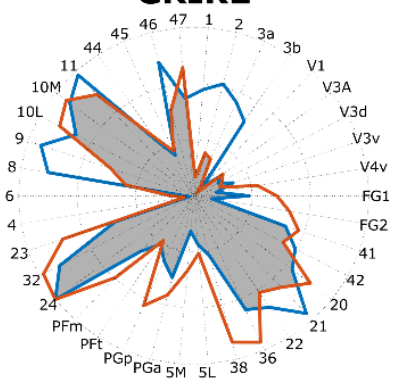

GABRA6

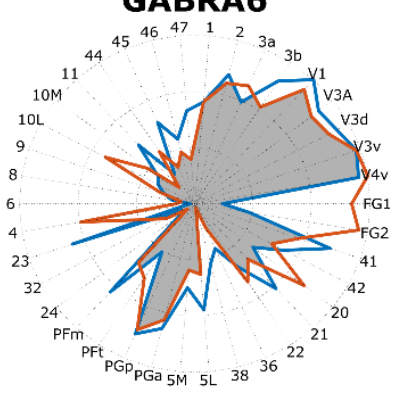

GABRG3

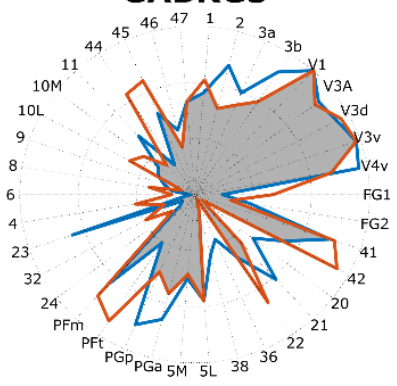

ADRA2A

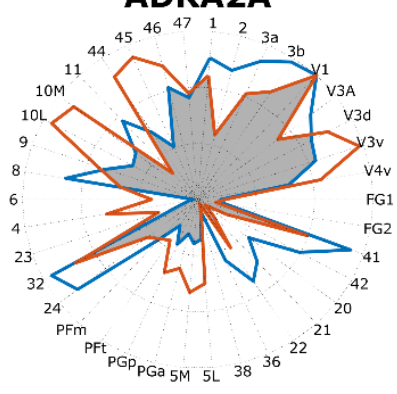

GABRB1

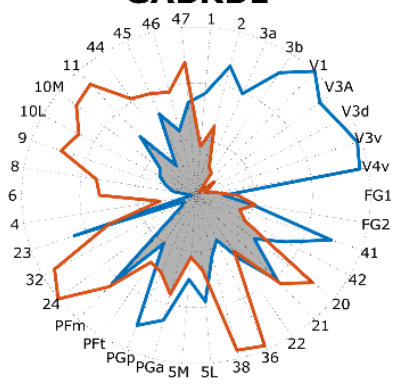

$\square$ overlap - autoRTG - pred-mRNA

Figure 2: Radar plots showing the relation between interpolated transcriptomic data and autoradiography for significantly a) positive b) negative correlated receptors and gene expressions. 


\subsection{Microarray-based mRNA expression}

Complementary analyses, utilizing readily available microarray-based transcriptomic data of the AHBA database, are performed to further investigate the relationship between mRNA expression and protein concentration. Similar to the results with predicted mRNA patterns, we find positive links (Figure 3a) for kainate receptor and GRIK1, GRIK2; GABA receptor and GABRA1, GABRA4, GABRB2, GABRG2 and serotonin $1 A$ receptor and $H T R 1 A$, while negative associations (Figure $3 b$ ) are unveiled for GABA receptor and GABRA3, GABRA5 and GABRB1, showing significant strong correlations (Table 3). The majority of the gene expressions show again low and not significant relations with receptor distributions (Supl. table 2-6).
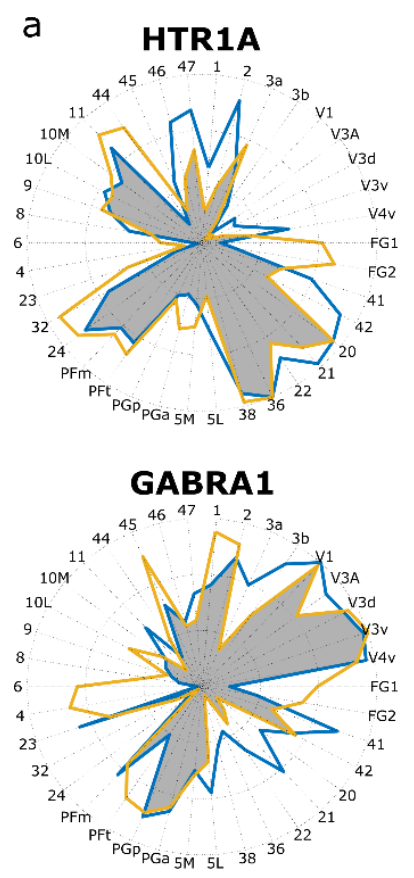

b

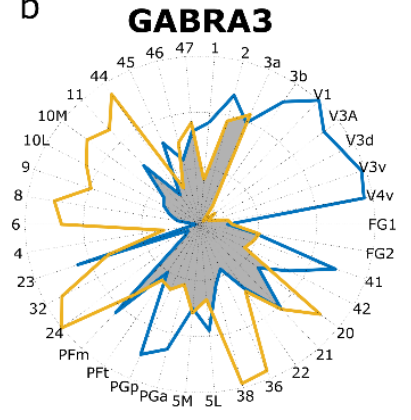

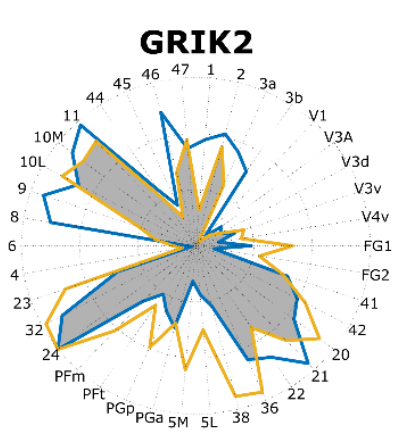

GABRA4
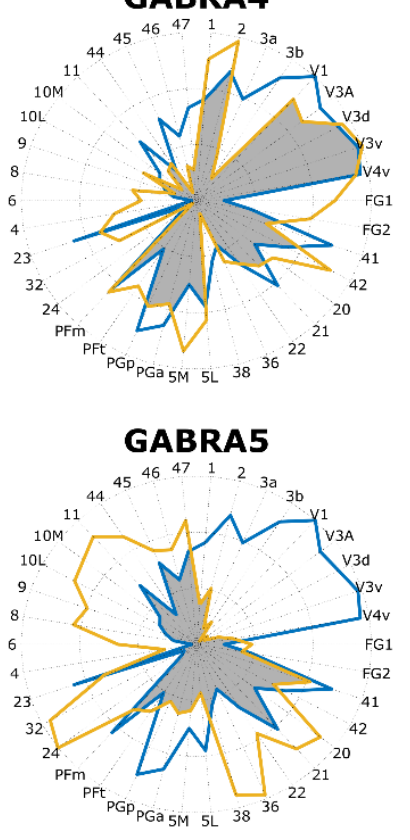

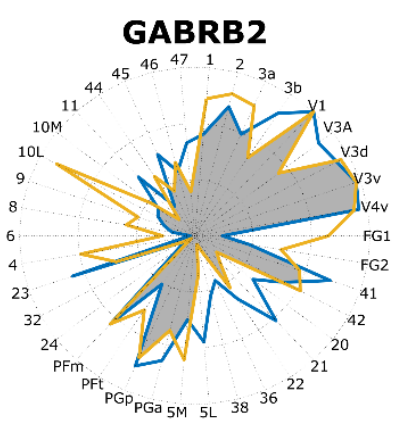

GABRG2

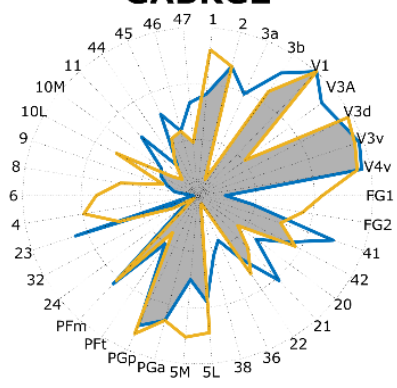

GABRB1

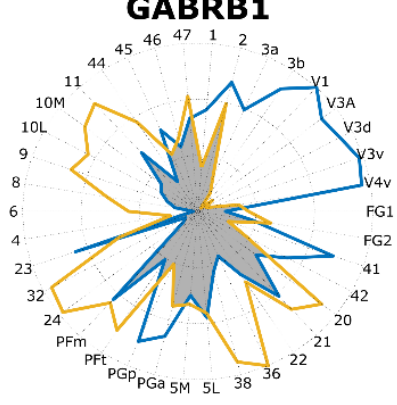

overlap - autoRTG $-\mathrm{mA}$

Figure 3: Radar plots showing the relation between microarray transcriptomic data and autoradiography for significantly a) positive b) negative correlated receptors and gene expressions. 


\begin{tabular}{|l|l|l|l|l|}
\hline Receptor & Gene ID & Gene & $\mathbf{r}_{\mathrm{S}}$ & p $_{\mathrm{SA}}$ \\
\hline 5-HT ${ }_{1 A}$ & HTR1A & serotonin receptor 1A & 0.601 & 0.014 \\
\hline $\mathrm{GABA}_{A}$ & GABRG2 & $\mathrm{GABA}_{A}$ receptor subunit $\gamma 2$ & 0.57 & 0.015 \\
\hline $\mathrm{GABA}_{A}$ & GABRB2 & $\mathrm{GABA}_{A}$ receptor subunit $\beta 2$ & 0.569 & 0.012 \\
\hline $\mathrm{GABA}_{A}$ & GABRA4 & $\mathrm{GABA}_{A}$ receptor subunit $\alpha 4$ & 0.532 & 0.029 \\
\hline $\mathrm{GABA}_{A}$ & GABRA1 & $\mathrm{GABA}_{A}$ receptor subunit $\alpha 1$ & 0.513 & 0.041 \\
\hline Kainate & GRIK2 & Glu ionotropic receptor kainate type subunit 2 & 0.597 & 0.023 \\
\hline $\mathrm{GABA}_{A}$ & GABRA3 & $\mathrm{GABA}_{A}$ receptor subunit $\alpha 3$ & -0.619 & 0.002 \\
\hline $\mathrm{GABA}_{A}$ & GABRA5 & $\mathrm{GABA}_{A}$ receptor subunit $\alpha 5$ & -0.563 & 0.021 \\
\hline $\mathrm{GABA}_{A}$ & GABRB1 & $\mathrm{GABA}_{A}$ receptor subunit $\beta 1$ & -0.537 & 0.027 \\
\hline
\end{tabular}

Table 3: Gene expressions represented by microarray data significantly $\left(p_{S A}<0.05\right)$ correlated with receptor distributions. Negative correlations are listed at the bottom of the table.

\subsection{RNA-Seq}

A further follow-up analysis is looking into the correlation of RNA-Seq data AHBA and target receptor densities. Here, a host of the relations is not significant, yielding only two positive and two negative significant and strong correlations (Table 4). Kainate receptor distribution is positively linked with GRIK1 as well as $\mathrm{GABA}_{B}$ receptor is positively correlated with GABBR1 (Figure 4a). On the other hand, we find negative associations between adrenoceptor $\alpha 1$ and $A D R A 1 A$ together with $G A B A_{A}$ receptor and GABRQ (Figure 4b). Overview of the comparison between RNA-Seq and other microarray-based datasets is in the supplementary table 7. 
a

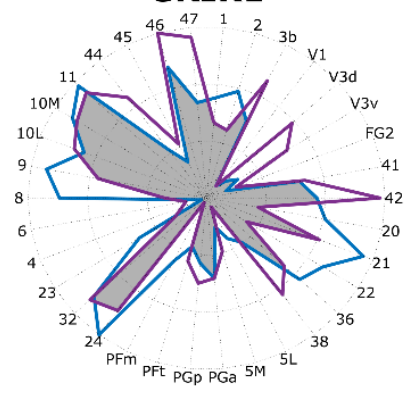

b

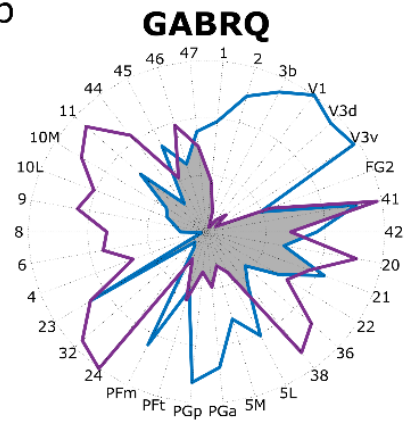

GABBR1

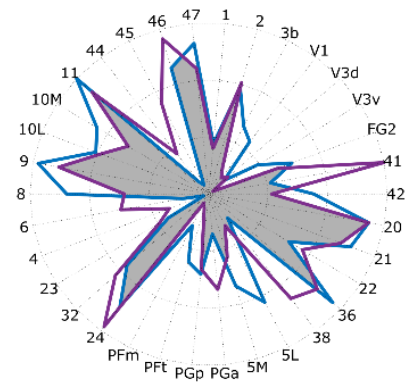

ADRA1A

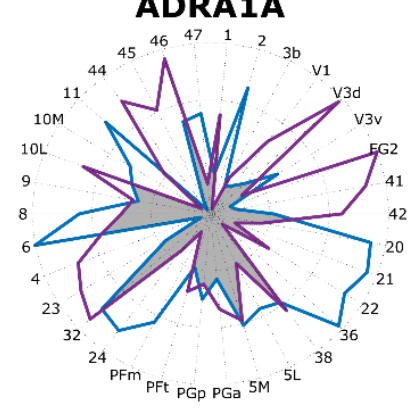

$\square$ overlap - autoRTG - RNASeq

Figure 4: Radar plots showing the relation between RNA-Seq data and autoradiography for significantly a) positive b) negative correlated receptors and gene expressions.

\begin{tabular}{|l|l|l|l|l|}
\hline Receptor & Gene ID & Gene & $\mathbf{r}_{\mathrm{S}}$ & $\mathbf{p}_{\mathrm{SA}}$ \\
\hline $\mathrm{GABA}_{\mathrm{B}}$ & GABBR1 & GABA $_{B}$ receptor subunit 1 & 0.586 & 0.008 \\
\hline Kainate & GRIK1 & Glu ionotropic receptor kainate type subunit 1 & 0.575 & 0.036 \\
\hline $\mathrm{GABA}_{\mathrm{A}}$ & GABRQ & GABA $_{\mathrm{A}}$ receptor subunit $\theta$ & -0.613 & 0.002 \\
\hline$\alpha_{1}$ & ADRA1A & adrenoceptor $\alpha 1 \mathrm{~A}$ & -0.503 & 0.030 \\
\hline
\end{tabular}

Table 4: Gene expressions represented RNASeq data significantly $\left(p_{S A}<0.05\right)$ correlated with receptor distributions. Negative correlations are listed at the bottom of the table. 


\section{Discussion}

In this work, we demonstrate associations between mRNA expression and associated protein density patterns for multiple neuroreceptors of the human cerebral cortex. Analysis unveil statistically significant positive correlations across brain areas for some receptors that have been already known to show topological associations with their gene expressions based on PET data, e.g.the serotonin $1 \mathrm{~A}$ receptor (Komorowski et al., 2017; Unterholzner et al., 2020). Similarly, kainate receptor showed significant similarities in the spatial distribution of receptor densities and mRNA expression patterns of subunits GluK1 and GluK2 (GRIK1, GRIK2). These are allowing for the formation of homomeric receptors and show different pharmacological properties as the rest of the subunits (Fisher and Fisher, 2014). On the other hand, a previously shown strong correlation between gene expression and PET measured receptor distribution of e.g. serotonin 2A receptor (Komorowski et al., 2017) was not confirmed here. This discrepancy might come from the different origin of the proteomic data that is subunit specific for PET, while autoradiography is quantifying the distribution of the whole $5-\mathrm{HT}_{2}$ receptor.

Counterintuitively, cortical distributions of receptors and their expression patterns also showed a few strong negative relations suggesting a solid, indirect relation underlining the possibility of intricate regulatory circuitry at an intermediate level between mRNA expression and translation. Despite several significant results, most of the comparisons yield weak, statistically not significant correlations between transcriptomic and proteomic information. The results revealed by our analysis fit the outcomes of previous publications correlating PET and mRNA data (Godbersen et al., 2021; Maier et al., 2009)

The differences in correlation observed between variety receptor targets have been attributed to a multitude of factors in the recent past. Foremost is the post-translational modifications (PTMs), which can lead to an apparent local mismatch of mRNA expression to the gene product. The biological need for such modifications arises with the relatively long half-life of eukaryotic mRNA and therefore the need to regulate resulting protein levels in short time frames (Raghavan et al., 2002). This, on a 
biological level, can be achieved by influencing, for example, translational efficiency and the rate of protein degradation as well as a host of other effects elicited by PTMs. The total extent of influences at different steps in translation may vary significantly between organisms, cell populations and metabolic states where overabundance or lack of available ribosomes might play a decisive role in determining resulting concentrations of the gene product (Hershey et al., 2012). Factors that proved to play a major role here are ribosome transit times (Fan and Penman, 1970) and polysome profiles, which both offer additional information regarding the phase of protein synthesis affected by specific changes. In addition, posttranslational translocation of the proteins may also play an integral role in PTMs affecting the spatial distribution of receptors (Johnson et al., 2013). These scientific undertakings helped reveal that translational control can be influenced on a global level, in a specific subset of mRNA, or on a level of single mRNA. Such global changes can be brought upon by modifications to the overall translational processes while even more specific changes can be mediated by microRNA or trans-acting proteins (Gebauer et al., 2012).

Furthermore, individual subunit transcripts might not always offer the same quality of surrogate for receptor distribution. A prime example for this is the $\mathrm{GABA}_{\mathrm{A}}$ receptor, which is a complex pentamer usually made up of distinct subunit, $\alpha(1-6), \beta(1-4), \gamma(1-3), \delta, \varepsilon, \theta, \pi$ and $\rho(1-3)$. The most abundant isomer in the human cerebral cortex is typically comprised of two $\alpha 1$, two $\beta 2$ and one $\gamma 2$ subunit(s) (Macdonald and Olsen, 1994; Olsen and Sieghart, 2008). Next to this most frequent pentamer, multiple other isoforms have been detected (Farrar et al., 1999; Tretter et al., 1997). Noteworthy, gene expression patterns of all three aforementioned subunits show a strong, positive significant correlation with $\mathrm{GABA}_{\mathrm{A}}$ receptor distribution. While distinct variants make up most of the regional receptor populations, parts of the brain show different expression patterns leaving $\alpha 1 \beta 2 \gamma 2$ isomer as an exception rather than the rule. Namely, several $\mathrm{GABA}_{A}$ subunits $(\alpha 3, \alpha 5, \beta 1)$ show significantly negative correlations between receptor distribution and its gene expressions. This discrepancy could be possibly attributed to the most abundant subunits that might mask the real correlation between receptor subunits and their gene expression. Besides subtype variants, for GABA-receptors extensive post- 
translational modifications have been demonstrated offering an additional venue for effective decoupling of mRNA expression and resulting protein concentration (Campbell and Tyagarajan, 2019).

The origin of unexpected low correlation values might also lie on the side of the autoradiography dataset. Previous studies have already proven that concentrations of endogenous neurotransmitters can significantly affect the radioligand binding to its target suggesting that measured protein distribution might be not representative (Sasaki et al., 2002). Moreover, as previously suggested for the $\mathrm{GABA}_{\mathrm{A}}$ or $5-\mathrm{HT}_{2}$ receptors, the masking effect of the most abundant subunits and subtypes might affect the correlation. For example, $\left[{ }^{3} \mathrm{H}\right]$-Epibatidine used for labeling nicotinic $\alpha_{4} \beta_{2}$ receptor is an agonist for subunits $\alpha_{2}-\alpha_{7}$ binding to all of them with similar affinity (Gaulton et al., 2017). In particular, alongside the $\alpha_{4} \beta_{2}$ receptor, the homomeric $\alpha_{7}$ receptor which is also widely present across the brain (Gotti et al., 2006), might cause masking of the real $\alpha_{4}$ distribution. On the other hand [ $\left.{ }^{3} \mathrm{H}\right] 8-\mathrm{OH}-\mathrm{DPAT}$, a highly specific ligand for $5-\mathrm{HT}_{1 \mathrm{~A}}$ receptor has a lower affinity to other $5-\mathrm{HT}_{1}$ subtypes (NewmanTancredi et al., 1998), which is further supported by the strong correlation between its spatial distribution and gene expression. These discrepancies in the binding of ligands suggest, that poor correlation between most of the receptor distribution and gene expression patterns might be affected by different affinities to individual receptor subunits.

To fully grasp the picture of protein abundance resulting from mRNA expression patterns, it is imperative to evaluate not only total protein and mRNA in corresponding samples, ideally from the same donor, but to also quantify each step of protein synthesis along the way. This will require significant effort, as methods for global identification and quantification of both transcriptome and resulting translatome still require a high level of expertise in experimental design and methodical calculations (Arnatkevičiūtè et al., 2019). Nowadays, most of microarray data limitations might be overcome by employing next generation sequencing data (Stark et al., 2019; Wang et al., 2009), enabling high throughput parallel sequence detection enabling procedural counting of transcripts to allow for direct quantification. However, using additional data set of RNA-Seq data for comparison to receptor distributions confirmed only a couple of results coming from microarray data analysis (e.g. 
for kainate receptor subunit 1 or $G_{A B A}$ receptor subunit $\alpha 5$ ) while most of the results were not significant which can be accounted to rather scarce RNA-Seq data set of AHBA. The limited information contained in the RNA-Seq AHBA data is further upheld by the counterintuitive results of the comparison to microarray data sets, showing a rather weak correlation for most of the investigated gene expressions highlight for more comprehensive RNA-Seq database. Ultimately, methods like span single cell in vivo experiments and high throughput sequencing experiments for mRNA might provide promising quantitative information to further uncover underlying links between receptor distributions and mRNA levels.

\subsection{Limitations:}

Firstly, besides the commonly known limitation of Allen Human Brain atlas genetic data sets (most of the sparsely distributed samples come from 6 left hemispheres while only 2 right hemispheres are available), the autoradiography data set stems from a different set of donors than the transcriptomic data. While we can partially account for the Allen Human Brain atlas limitations by mirroring the samples along the sagittal plane and using the predicted cortical mRNA expression patterns (Gryglewski et al., 2020), the inter-subject variability between transcriptomic and proteomic data sources could not be resolved. Additionally, at this point, it appears that the problem of subdividing used autoradiographic signals to the corresponding receptor subtypes remains unsolvable, without further measurements using subunit-specific tracers. It is known that subtypes of neuro-receptors exhibit different binding potentials - therefore, it cannot be ruled out in these cases, that the majority of the signal is due to a single variant, subunit or conformation, which confers way stronger binding than its counterparts. This fact diminishes the overall explanatory power of the analysis at hand but also illustrates the need for more advanced models to allow for the estimation of specific protein abundancy.

\section{Conclusion:}

In the present work, we report a comparison of available high-quality data characterizing cortical receptor distribution at the level of mRNA expression as well as protein abundance. We identified 
several positive as well as negative links between the scrutinized modalities, however, most of the comparisons showed no direct relation between protein density and transcriptomic information.

Current results show that gene expression should not be directly used as a surrogate for protein distribution rather as additional information in multimodal studies to further investigate the effect of numerous processes happening on the way from mRNA to protein. The role of posttranscriptional processes and posttranslational modification cannot be ignored and should motivate further studies on potential mRNA markers associated with them. 


\section{Data availability statement}

Due to data protection laws, processed data is available from the authors upon reasonable request. Please contact rupert.lanzenberger@meduniwien.ac.at with any questions or requests.

\section{Acknowledgements}

M. Murgaš is funded by the Austrian Science Fund FWF, DOC 33-B27. MB. Reed is a recipient of a DOC fellowship of the Austrian Academy of Sciences at the Department of Psychiatry and Psychotherapy, Medical University of Vienna. We would like to thank Prof. Zilles ( + ), Prof. Amunts and Dr. PalomeroGallagher of the Research Centre Jülich, Institute of Neuroscience and Medicine (INM-1), Jülich, Germany, (Zilles and Palomero-Gallagher, 2017), as well as the Allen Institute for Brain Science, Seattle, USA (Hawrylycz et al., 2012) for making their valuable data sets publicly available.

\section{Conflicts of Interest}

With relevance to this work, there is no conflict of interest to declare. R. Lanzenberger received travel grants and/or conference speaker honoraria within the last three years from Bruker BioSpin MR, Heel, and support from Siemens Healthcare regarding clinical research using PET/MR. He is a shareholder of the start-up company BM Health GmbH since 2019. Matej Murgaš, Paul Michenthaler, Murray B. Reed and Gregor Gryglewski have no conflicts of interest to declare. 


\section{REFERENCES}

ALLEN Human Brain Atlas, 2013. TECHNICAL WHITE PAPER: CASE QUALIFICATION AND DONOR PROFILES [white paper] . URL http://help.brain-

map.org/download/attachments/2818165/CaseQual_and_DonorProfiles.pdf

Amunts, K., Mohlberg, H., Bludau, S., Zilles, K., 2020. Julich-Brain: A 3D probabilistic atlas of the human brain's cytoarchitecture. Science (80-. ). 369, 988 LP - 992. https://doi.org/10.1126/science.abb4588

Arnatkevičiūtè, A., Fulcher, B.D., Fornito, A., 2019. A practical guide to linking brain-wide gene expression and neuroimaging data. Neuroimage 189, 353-367.

https://doi.org/10.1016/j.neuroimage.2019.01.011

Baldinger-Melich, P., Gryglewski, G., Philippe, C., James, G.M., Vraka, C., Silberbauer, L., Balber, T., Vanicek, T., Pichler, V., Unterholzner, J., Kranz, G.S., Hahn, A., Winkler, D., Mitterhauser, M., Wadsak, W., Hacker, M., Kasper, S., Frey, R., Lanzenberger, R., 2019. The effect of electroconvulsive therapy on cerebral monoamine oxidase $A$ expression in treatment-resistant depression investigated using positron emission tomography. Brain Stimul. 12, 714-723. https://doi.org/10.1016/j.brs.2018.12.976

Beliveau, V., Ganz, M., Feng, L., Ozenne, B., Højgaard, L., Fisher, P.M., Svarer, C., Greve, D.N., Knudsen, G.M., 2017. A High-Resolution In Vivo Atlas of the Human Brain's Serotonin System. J. Neurosci. 37, 120-128. https://doi.org/10.1523/JNEUROSCI.2830-16.2016

Burt, J.B., Helmer, M., Shinn, M., Anticevic, A., Murray, J.D., 2020. Generative modeling of brain maps with spatial autocorrelation. Neuroimage 220, 117038. https://doi.org/10.1016/J.NEUROIMAGE.2020.117038

Campbell, B.F.N., Tyagarajan, S.K., 2019. Cellular Mechanisms Contributing to the Functional Heterogeneity of GABAergic Synapses. Front. Mol. Neurosci. 12, 187. https://doi.org/10.3389/FNMOL.2019.00187/BIBTEX

Cohen, J., 1992. A power primer. Psychol. Bull. 112, 155-159. https://doi.org/10.1037/00332909.112.1.155

Cosci, F., Chouinard, G., 2019. The monoamine hypothesis of depression revisited: Could it mechanistically novel antidepressant strategies?, in: Neurobiology of Depression: Road to Novel Therapeutics. Elsevier, pp. 63-73. https://doi.org/10.1016/B978-0-12-813333-0.00007-X

Fan, H., Penman, S., 1970. Regulation of protein synthesis in mammalian cells: II. Inhibition of protein synthesis at the level of initiation during mitosis. J. Mol. Biol. 50, 655-670.

https://doi.org/10.1016/0022-2836(70)90091-4

Farrar, S.J., Whiting, P.J., Bonnert, T.P., McKernan, R.M., 1999. Stoichiometry of a ligand-gated ion channel determined by fluorescence energy transfer. J. Biol. Chem. 274, 10100-10104. https://doi.org/10.1074/jbc.274.15.10100

Filippi, L., Schillaci, O., Bagni, O., 2019. Recent advances in PET probes for hepatocellular carcinoma characterization. Expert Rev. Med. Devices 16, 341-350. https://doi.org/10.1080/17434440.2019.1608817

Fisher, M.T., Fisher, J.L., 2014. Contributions of different kainate receptor subunits to the properties of recombinant homomeric and heteromeric receptors. Neuroscience 278, 70. https://doi.org/10.1016/J.NEUROSCIENCE.2014.08.009

Fulcher, B.D., Little, M.A., Jones, N.S., 2013. Highly comparative time-series analysis: the empirical 
structure of time series and their methods. J. R. Soc. Interface 10, 20130048. https://doi.org/10.1098/rsif.2013.0048

Gaulton, A., Hersey, A., Nowotka, M.L., Patricia Bento, A., Chambers, J., Mendez, D., Mutowo, P., Atkinson, F., Bellis, L.J., Cibrian-Uhalte, E., Davies, M., Dedman, N., Karlsson, A., Magarinos, M.P., Overington, J.P., Papadatos, G., Smit, I., Leach, A.R., 2017. The ChEMBL database in 2017. Nucleic Acids Res. 45, D945-D954. https://doi.org/10.1093/nar/gkw1074

Gebauer, F., Preiss, T., Hentze, M.W., 2012. From cis-regulatory elements to complex RNPs and back. Cold Spring Harb. Perspect. Biol. 4, a012245. https://doi.org/10.1101/cshperspect.a012245

Godbersen, G.M., Murgaš, M., Gryglewski, G., Klöbl, M., Unterholzner, J., Rischka, L., Spies, M., Baldinger-Melich, P., Winkler, D., Lanzenberger, R., 2021. Coexpression of gene transcripts with monoamine oxidase A quantified by human in vivo positron emission tomography. Cereb. Cortex. https://doi.org/10.1093/cercor/bhab430

Gotti, C., Zoli, M., Clementi, F., 2006. Brain nicotinic acetylcholine receptors: native subtypes and their relevance. Trends Pharmacol. Sci. 27, 482-491. https://doi.org/10.1016/J.TIPS.2006.07.004

Gryglewski, G., Murgaš, M., Michenthaler, P., Klöbl, M., Reed, M.B., Unterholzner, J., Lanzenberger, R., 2020. Enrichment of disease-associated genes in cortical areas defined by transcriptomebased parcellation. bioRxiv 2020.03.02.971911. https://doi.org/10.1101/2020.03.02.971911

Gryglewski, G., Seiger, R., James, G.M., Godbersen, G.M., Komorowski, A., Unterholzner, J., Michenthaler, P., Hahn, A., Wadsak, W., Mitterhauser, M., Kasper, S., Lanzenberger, R., 2018. Spatial analysis and high resolution mapping of the human whole-brain transcriptome for integrative analysis in neuroimaging. Neuroimage 176, 259-267. https://doi.org/10.1016/j.neuroimage.2018.04.068

Hawrylycz, M.J., Lein, E.S., Guillozet-Bongaarts, A.L., Shen, E.H., Ng, L., Miller, J.A., Van De Lagemaat, L.N., Smith, K.A., Ebbert, A., Riley, Z.L., Abajian, C., Beckmann, C.F., Bernard, A., Bertagnolli, D., Boe, A.F., Cartagena, P.M., Mallar Chakravarty, M., Chapin, M., Chong, J., Dalley, R.A., Daly, B.D., Dang, C., Datta, S., Dee, N., Dolbeare, T.A., Faber, V., Feng, D., Fowler, D.R., Goldy, J., Gregor, B.W., Haradon, Z., Haynor, D.R., Hohmann, J.G., Horvath, S., Howard, R.E., Jeromin, A., Jochim, J.M., Kinnunen, M., Lau, C., Lazarz, E.T., Lee, C., Lemon, T.A., Li, L., Li, Y., Morris, J.A., Overly, C.C., Parker, P.D., Parry, S.E., Reding, M., Royall, J.J., Schulkin, J., Sequeira, P.A., Slaughterbeck, C.R., Smith, S.C., Sodt, A.J., Sunkin, S.M., Swanson, B.E., Vawter, M.P., Williams, D., Wohnoutka, P., Ronald Zielke, H., Geschwind, D.H., Hof, P.R., Smith, S.M., Koch, C., Grant, S.G.N., Jones, A.R., 2012. An anatomically comprehensive atlas of the adult human brain transcriptome. Nature 489, 391-399. https://doi.org/10.1038/nature11405

Hershey, J.W.B., Sonenberg, N., Mathews, M.B., 2012. Principles of translational control: an overview. Cold Spring Harb. Perspect. Biol. 4. https://doi.org/10.1101/cshperspect.a011528

Holmes, C.J., Hoge, R., Collins, L., Woods, R., Toga, A.W., Evans, A.C., 1998. Enhancement of MR Images Using Registration for Signal Averaging. J. Comput. Assist. Tomogr. 22. https://doi.org/10.1097/00004728-199803000-00032

Horton, R.W., 1992. The neurochemistry of depression: Evidence derived from studies of postmortem brain tissue. Mol. Aspects Med. 13, 191-203. https://doi.org/10.1016/00982997(92)90009-0

Johnson, N., Powis, K., High, S., 2013. Post-translational translocation into the endoplasmic reticulum. Biochim. Biophys. Acta - Mol. Cell Res. 1833, 2403-2409.

https://doi.org/10.1016/J.BBAMCR.2012.12.008 
Komorowski, A., James, G.M., Philippe, C., Gryglewski, G., Bauer, A., Hienert, M., Spies, M., Kautzky, A., Vanicek, T., Hahn, A., Traub-Weidinger, T., Winkler, D., Wadsak, W., Mitterhauser, M., Hacker, M., Kasper, S., Lanzenberger, R., 2017. Association of protein distribution and gene expression revealed by PET and post-mortem quantification in the serotonergic system of the human brain. Cereb. Cortex 27, 117-130. https://doi.org/10.1093/cercor/bhw355

Komorowski, A., Vidal, R., Singh, A., Murgaš, M., Pena-Centeno, T., Gryglewski, G., Kasper, S., Wiltfang, J., Lanzenberger, R., Goya-Maldonado, R., 2020a. Regional gene expression patterns are associated with task-specific brain activation during reward and emotion processing measured with functional MRI. bioRxiv 2020.06.27.175257. https://doi.org/10.1101/2020.06.27.175257

Komorowski, A., Weidenauer, A., Murgaš, M., Sauerzopf, U., Wadsak, W., Mitterhauser, M., Bauer, M., Hacker, M., Praschak-Rieder, N., Kasper, S., Lanzenberger, R., Willeit, M., 2020b. Association of dopamine D2/3 receptor binding potential measured using PET and [11C]-(+)-PHNO with post-mortem DRD2/3 gene expression in the human brain. Neuroimage 223, 117270. https://doi.org/https://doi.org/10.1016/j.neuroimage.2020.117270

Lamers, F., Van Oppen, P., Comijs, H.C., Smit, J.H., Spinhoven, P., Van Balkom, A.J.L.M., Nolen, W.A., Zitman, F.G., Beekman, A.T.F., Penninx, B.W.J.H., 2011. Comorbidity patterns of anxiety and depressive disorders in a large cohort study: The Netherlands Study of Depression and Anxiety (NESDA). J. Clin. Psychiatry 72, 342-348. https://doi.org/10.4088/JCP.10m06176blu

Lohith, T.G., Tsujikawa, T., Siméon, F.G., Veronese, M., Zoghbi, S.S., Lyoo, C.H., Kimura, Y., Morse, C.L., Pike, V.W., Fujita, M., Innis, R.B., 2017. Comparison of two PET radioligands, [11C]FPEB and [11C]SP203, for quantification of metabotropic glutamate receptor 5 in human brain. J. Cereb. Blood Flow Metab. 37, 2458-2470. https://doi.org/10.1177/0271678X16668891

Lu, R.C., She, B., Gao, W.T., Ji, Y.H., Xu, D.D., Wang, Q.S., Wang, S.B., 2019. Positron-emission tomography for hepatocellular carcinoma: Current status and future prospects. World J. Gastroenterol. 25, 4682-4695. https://doi.org/10.3748/wjg.v25.i32.4682

Lui, S., Zhou, X.J., Sweeney, J.A., Gong, Q., 2016. Psychoradiology: The frontier of neuroimaging in psychiatry. Radiology 281, 357-372. https://doi.org/10.1148/radiol.2016152149

Macdonald, R.L., Olsen, R.W., 1994. GABAA Receptor Channels. Annu. Rev. Neurosci. 17, 569-602. https://doi.org/10.1146/annurev.ne.17.030194.003033

Maier, T., Güell, M., Serrano, L., 2009. Correlation of mRNA and protein in complex biological samples. FEBS Lett. 583, 3966-3973. https://doi.org/10.1016/j.febslet.2009.10.036

Murgas, M., Michenthaler, P., Gryglewski, G., Lanzenberger, R., 2021a. Association of receptor distributions with mRNA patterns in human cerebral cortex [abstract] . 16th PhD-Symposium Young Sci. Assoc. URL https://ysa.meduniwien.ac.at/phd-symposium/phd-symposium2021/abstract-overview-2021/?tx_cagtables_pi1\%5Bdetail\%5D=115

Murgas, M., Michenthaler, P., Gryglewski, G., Lanzenberger, R., 2021b. Receptor distribution associations to mRNA gene expression patterns in the human cerebral cortex [abstract] . XIII Int. Symp. Funct. Neurorecept. Mapp. Living Brain Mapp. Neurorecept. Work. P-TH-10-01.

Murgas, M., Michenthaler, P., Gryglewski, G., Lanzenberger, R., 2020. Topological comparison of receptor densities and mRNA expression in the cerebral cortex. [abstract] . 3rd MIC Festiv. Driv. Evol. Med. with Imaging. URL https://www.meduniwien.ac.at/web/fileadmin/_processed_/3/e/csm_23_Poster_MIC2020_M urgas_435fc541af.jpg 
Murgas, M., Michenthaler, P., Gryglewski, G., Lanzenberger, R., Reed, M.B., Gryglewski, G., Lanzenberger, R., 2021c. Topological comparison of mRNA expression patterns with receptor distributions in the human cerebral cortex [abstract] . 17th Austrian Neurosci. Assoc. Meet. P11. URL https://www.austrian-neuroscience.at/news/11119985

Newman-Tancredi, A., Verriéle, L., Chaput, C., Millan, M.J., 1998. Labelling of recombinant human and native rat serotonin 5-HT1A receptors by a novel, selective radioligand, [3H]-S 15535: definition of its binding profile using agonists, antagonists and inverse agonists. Naunyn. Schmiedebergs. Arch. Pharmacol. 357, 205-217. https://doi.org/10.1007/PL00005159

Olsen, R.W., Sieghart, W., 2008. International Union of Pharmacology. LXX. Subtypes of $\gamma^{-}$ Aminobutyric Acid\&lt;sub\&gt;A\&lt;/sub\&gt; Receptors: Classification on the Basis of Subunit Composition, Pharmacology, and Function. Update. Pharmacol. Rev. 60, 243 LP - 260. https://doi.org/10.1124/pr.108.00505

Raghavan, A., Ogilvie, R.L., Reilly, C., Abelson, M.L., Raghavan, S., Vasdewani, J., Krathwohl, M., Bohjanen, P.R., 2002. Genome-wide analysis of mRNA decay in resting and activated primary human T lymphocytes. Nucleic Acids Res. 30, 5529-5538. https://doi.org/10.1093/nar/gkf682

Rainer, Q., Xia, L., Guilloux, J.-P., Gabriel, C., Mocaër, E., Hen, R., Enhamre, E., Gardier, A.M., David, D.J., 2012. Beneficial behavioural and neurogenic effects of agomelatine in a model of depression/anxiety. Int. J. Neuropsychopharmacol. 15, 321-335. https://doi.org/10.1017/S1461145711000356

Sasaki, T., Ishiwata, K., Murata, T., Senda, M., 2002. Demonstration of competition between endogenous dopamine and [11C]raclopride binding in in vitro brain slices using a dynamic autoradiography technique. Synapse 44, 42-50. https://doi.org/10.1002/SYN.10051

Shen, E.H., Overly, C.C., Jones, A.R., 2012. The Allen Human Brain Atlas: Comprehensive gene expression mapping of the human brain. Trends Neurosci. 35, 711-714. https://doi.org/10.1016/j.tins.2012.09.005

Spies, M., James, G.M., Vraka, C., Philippe, C., Hienert, M., Gryglewski, G., Komorowski, A., Kautzky, A., Silberbauer, L., Pichler, V., Kranz, G.S., Nics, L., Balber, T., Baldinger-Melich, P., Vanicek, T., Spurny, B., Winkler-Pjrek, E., Wadsak, W., Mitterhauser, M., Hacker, M., Kasper, S., Lanzenberger, R., Winkler, D., 2018. Brain monoamine oxidase A in seasonal affective disorder and treatment with bright light therapy. Transl. Psychiatry 8, 1-9.

https://doi.org/10.1038/s41398-018-0227-2

Stark, R., Grzelak, M., Hadfield, J., 2019. RNA sequencing: the teenage years. Nat. Rev. Genet. https://doi.org/10.1038/s41576-019-0150-2

Tretter, V., Ehya, N., Fuchs, K., Sieghart, W., 1997. Stoichiometry and Assembly of a Recombinant GABA A Receptor Subtype. J. Neurosci. 17, 2728 LP - 2737. https://doi.org/10.1523/JNEUROSCl.17-08-02728.1997

Unterholzner, J., Gryglewski, G., Philippe, C., Seiger, R., Pichler, V., Godbersen, G.M., BerroteránInfante, N., Murgaš, M., Hahn, A., Wadsak, W., Markus, M., Siegfried, K., Rupert, L., 2020. Topologically Guided Prioritization of Candidate Gene Transcripts Coexpressed with the 5-HT1A Receptor by Combining In Vivo PET and Allen Human Brain Atlas Data. Cereb. Cortex 30, 37713780 .

Villas Boas, G.R., Boerngen de Lacerda, R., Paes, M.M., Gubert, P., Almeida, W.L. da C., Rescia, V.C., de Carvalho, P.M.G., de Carvalho, A.A.V., Oesterreich, S.A., 2019. Molecular aspects of depression: A review from neurobiology to treatment. Eur. J. Pharmacol. https://doi.org/10.1016/j.ejphar.2019.02.024 
Wang, C., Gong, B., Bushel, P.R., Thierry-Mieg, J., Thierry-Mieg, D., Xu, J., Fang, H., Hong, H., Shen, J., Su, Z., Meehan, J., Li, X., Yang, L., Li, H., Łabaj, P.P., Kreil, D.P., Megherbi, D., Gaj, S., Caiment, F., Van Delft, J., Kleinjans, J., Scherer, A., Devanarayan, V., Wang, J., Yang, Y., Qian, H.R., Lancashire, L.J., Bessarabova, M., Nikolsky, Y., Furlanello, C., Chierici, M., Albanese, D., Jurman, G., Riccadonna, S., Filosi, M., Visintainer, R., Zhang, K.K., Li, J., Hsieh, J.H., Svoboda, D.L., Fuscoe, J.C., Deng, Y., Shi, L., Paules, R.S., Auerbach, S.S., Tong, W., 2014. The concordance between RNA-seq and microarray data depends on chemical treatment and transcript abundance. Nat. Biotechnol. 32, 926-932. https://doi.org/10.1038/nbt.3001

Wang, Z., Gerstein, M., Snyder, M., 2009. RNA-Seq: A revolutionary tool for transcriptomics. Nat. Rev. Genet. https://doi.org/10.1038/nrg2484

Zilles, K., Palomero-Gallagher, N., 2017. Multiple transmitter receptors in regions and layers of the human cerebral cortex. Front. Neuroanat. 11, 78. https://doi.org/10.3389/fnana.2017.00078 